\title{
Study on Influencing Factors of Adsorption of Methylene Blue on Magnetic Graphene Oxide Composite
}

\author{
Yafeng $\mathrm{Li}^{1}$, Jiacheng $\mathrm{Li}^{1,{ }^{*}}$ and Binxin $\mathrm{Zhao}^{1}$ \\ ${ }^{1}$ Municipal and environmental engineering, Shenyang Jianzhu University, Shenyang, Liaoning, 110000, China
}

\begin{abstract}
In order to explore the optimal reaction conditions of magnetic graphene oxide composite materials for the treatment of methylene blue wastewater. By controlling the $\mathrm{pH}$ value, contact time, temperature, the amount of adsorbent added for comparative analysis, and finally determine the best operating conditions. The study showed that when the $\mathrm{pH}$ value was 7 , the contact time was $1440 \mathrm{~min}$, the reaction temperature was $25^{\circ} \mathrm{C}$, and the dosage of the adsorbent was $0.5 \mathrm{~g} / \mathrm{L}$, the treatment effect was the best. Parameter optimization can effectively improve the processing effect.
\end{abstract}

\section{Introduction}

Graphene Oxide is the precursor of graphene prepared by the graphite oxide-reduction method. It is exfoliated into a single-layer sheet after attacking, stirring, and ultrasonication by the graphite oxide dispersed in the liquid phase. ${ }^{[1]}$ The research of graphite oxide began in the 19 th century, and in the last few decades, it has received more attention because of graphene.Currently known graphite oxide methods mainly include: Brodie method, Standenmaier method and Hummers method.Their reaction principle is to first use strong inorganic acid (such as concentrated sulfuric acid, fuming $\mathrm{HNO} 3$, etc.) to treat the original graphite to form interlayer compounds, and then use strong oxidants (such as $\mathrm{KMnO} 4, \mathrm{KClO}$, etc.) for oxidation to achieve a higher degree.Compared with Brodie method and Standenmaier method, the preparation time of Hummers method is shorter and the safety factor is higher. It is the most commonly used graphite oxide method $^{[2-3]}$.Although graphene oxide has good adsorption performance, it still has many limitations in its practical application. For example, it is highly dispersed in water, and it is difficult to effectively separate it from water by conventional methods after adsorption. By loading the magnetic material, the adsorption material can be separated from the water quickly and effectively under the external magnetic field. Compared with the traditional separation method, the magnetic separation not only consumes less energy but is more efficient.At present, the preparation of magnetic graphene oxide has been extensively studied ${ }^{[4]}$. Based on magnetic graphene oxide, this article explores the influence of different environmental factors on its treatment effect.

\section{Results and analysis}

\subsection{The influence of $\mathrm{pH}$ value on adsorption test}

Set the conditions that remain unchanged in this experiment:methylene blue concentration is $99.6 \mathrm{mg} / \mathrm{L}$, original water color is about 1500 times, reaction temperature is $25^{\circ} \mathrm{C}, \mathrm{Fe}_{3} \mathrm{O}_{4} @ \mathrm{GO}$ dosage is $1 \mathrm{~g} / \mathrm{L}$, Contact time is $300 \mathrm{~min}$, Control the $\mathrm{pH}$ between 3-10, Measure the absorbance and chromaticity of the effluent under different $\mathrm{pH}$ conditions, and calculate the unit adsorption amount of adsorbate and methylene blue decolorization rate. The test results are shown in Figure 1 and Figure 2.

From the picture, we can see that the unit adsorption capacity of Fe3O4@GO composite and the decolorization rate of methylene blue are significantly affected by the $\mathrm{pH}$ value.In the process of increasing $\mathrm{pH}$ from 3 to 7, the unit adsorption capacity of the composite material increased from $60.8 \mathrm{mg} / \mathrm{L}$ to $86.83 \mathrm{mg} / \mathrm{L}$, and the decolorization rate increased from $60.67 \%$ to $86.80 \%$, which was a significant increase; When the $\mathrm{pH}$ is greater than 7, continue to increase the $\mathrm{pH}$, and the unit adsorption capacity and decolorization rate have not continued to undergo major changes.And it reaches the highest between 7-8, and there is a slight fluctuation in the unit adsorption capacity after it is greater than 8 , but the overall remains basically unchanged. 


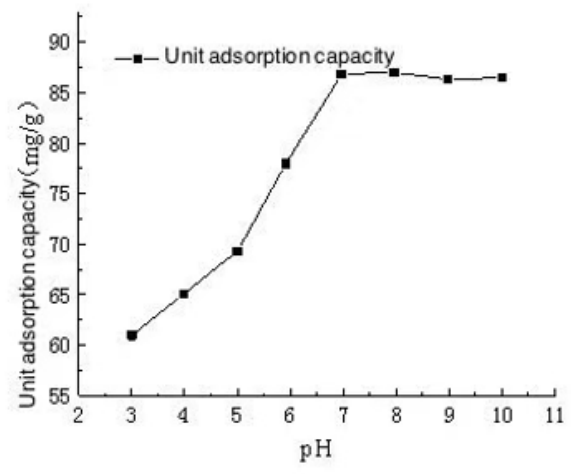

Fig1. Effect of $\mathrm{pH}$ value on Methylene Blue unit adsorption capacity of Fe3O4@GO

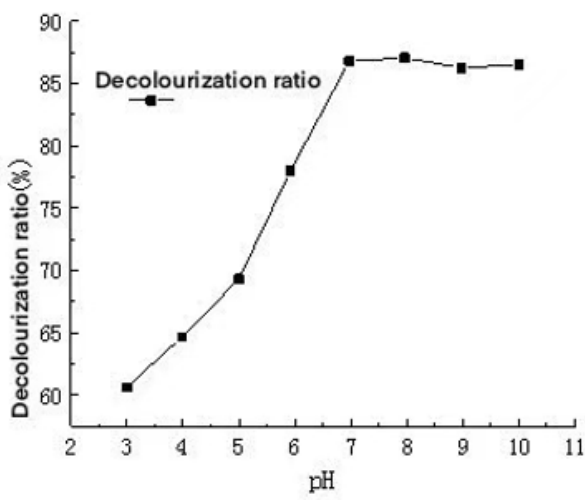

Fig2. Effect of $\mathrm{pH}$ value on decolorization rate of Methylene Blue adsorbed by $\mathrm{Fe}_{3} \mathrm{O}_{4} @$ GO

Therefore, we can think that it is favorable for $\mathrm{Fe}_{3} \mathrm{O}_{4} @ \mathrm{GO}$ to adsorb methylene blue in a neutral and alkaline environment, and the adsorption effect is best in a weak alkaline environment., At present, most scholars believe that the reason for this phenomenon is that under acidic conditions, the surface functional groups of $\mathrm{Fe}_{3} \mathrm{O}_{4} @ \mathrm{GO}$ materials are mostly negatively charged.The protons released in the water combine with the functional groups on the surface of the composite material due to the electrostatic force, thereby consuming part of the adsorption sites and forming an adsorption competition relationship with the methylene blue molecules.As the $\mathrm{pH}$ value increases, the neutralization reaction will deplete the free protons in the water, thereby increasing the amount of methylene blue adsorbed by the composite material[9]Some scholars also believe that:In the process of gradual increase in $\mathrm{pH}$, the charge of the surface groups of the composite material will change from positive to negative, This makes the positively charged methylene blue molecules easier to adsorb on the surface of the composite material, That is, the electrostatic force generated by $\mathrm{Fe}_{3} \mathrm{O}_{4} @ \mathrm{GO}$ material and methylene blue under neutral or acidic conditions is the main reason why the $\mathrm{pH}$ value affects the adsorption effect ${ }^{[5]}$

\subsection{The influence of contact time on adsorption test}

The conditions that remain unchanged in this experiment are set as follows: $\mathrm{pH}=6.92$, methylene blue concentration of $100.3 \mathrm{mg} / \mathrm{L}$, raw water chroma is about 1500 times, reaction temperature is $25^{\circ} \mathrm{C}, \mathrm{Fe}_{3} \mathrm{O}_{4} @ \mathrm{GO}$ dosage is $1 \mathrm{~g} / \mathrm{L}$,Experiments were performed in different reaction times to measure the absorbance and chromaticity of water, and calculate the unit adsorption amount of adsorbate and the decolorization rate of methylene blue.Determine the reaction time for the adsorption to reach equilibrium. The test results are shown in Figure 3 and Figure 4.

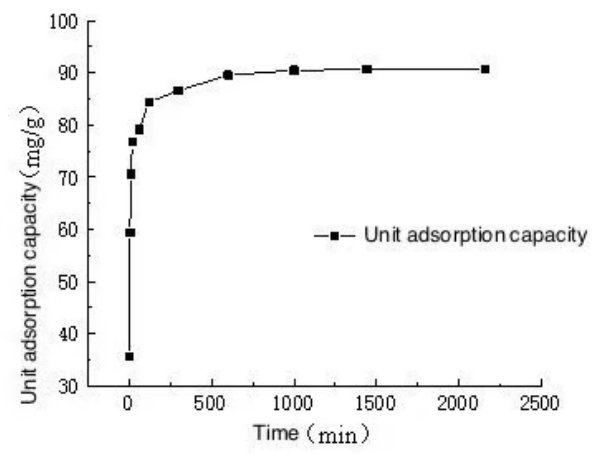

Fig3. Effect of Contact time on Methylene Blue unit adsorption capacity ofFe3O4@GO

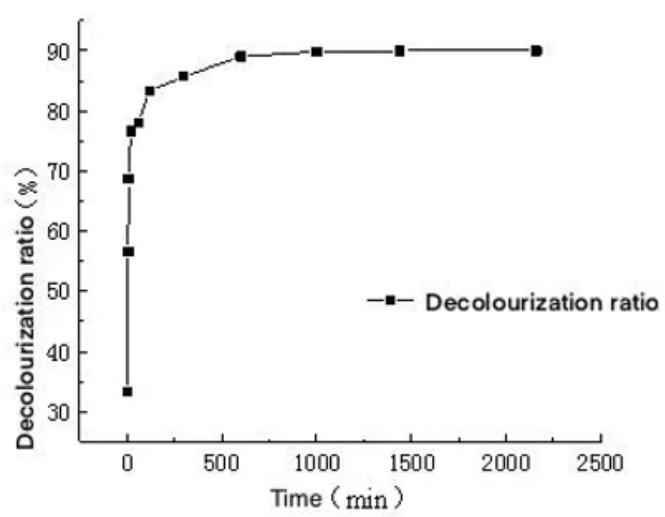

Fig4. Effect of Contact time on decolorization rate of Methylene Blue adsorbed by Fe3O4@GO

From the picture, we can see that the unit adsorption and decolorization rate increase rapidly in the first 20 minutes of $\mathrm{Fe}_{3} \mathrm{O}_{4} @ \mathrm{GO}$ contact.At 20 minutes, the unit adsorption capacity and decolorization rate reached $76.75 \mathrm{mg} / \mathrm{g}$ and $76.66 \%$ respectively; after 20 minutes, the growth rate slowed down and the curve gradually became flat; When the contact time reaches 1000 minutes, the adsorption basically reaches equilibrium. At this time, the unit adsorption amount and decolorization rate are $90.51 \mathrm{mg} / \mathrm{L}$ and $90.67 \%$, respectively.

The reason may be that at the beginning of the reaction, the content of methylene blue molecules in the raw water is high, and the adsorption sites on the $\mathrm{Fe}_{3} \mathrm{O}_{4} @ \mathrm{GO}$ material surface are sufficient, so that methylene blue can quickly and fully bind with the adsorption sites on the $\mathrm{Fe}_{3} \mathrm{O}_{4} @ \mathrm{GO}$ surface to form stable chemical bonds. With the increase of the reaction time, the concentration of 
methylene blue in the solution becomes lower, and the adsorption sites on the surface of $\mathrm{Fe}_{3} \mathrm{O}_{4} @ \mathrm{GO}$ become less, so that the effective contact of methylene blue molecules on the surface of $\mathrm{Fe}_{3} \mathrm{O}_{4} @ \mathrm{GO}$ becomes less, and the adsorption speed also becomes slower.

\subsection{The influence of reaction temperature on adsorption test}

Set the conditions that remain unchanged in this experiment: the methylene blue concentration is: $\mathrm{pH}=7.04$, $99.6 \mathrm{mg} / \mathrm{L}$, the original water color is about 1500 times, the dosage of Fe3O4@GO is $0.1 \mathrm{~g} / \mathrm{L}$, and the contact time is 1440 min..Control the reaction temperature at $15^{\circ} \mathrm{C}$ $35^{\circ} \mathrm{C}$. Measure the absorbance and chromaticity of the effluent at different reaction temperatures, and calculate the unit adsorption amount of adsorbate and the methylene blue decolorization rate. The test results are shown in Figure 5 and 6.

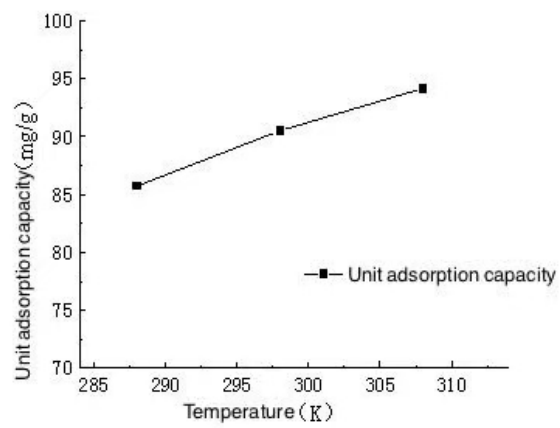

Fig5. Effect of temperature on Methylene Blue unit adsorption capacity of Fe3O4@GO

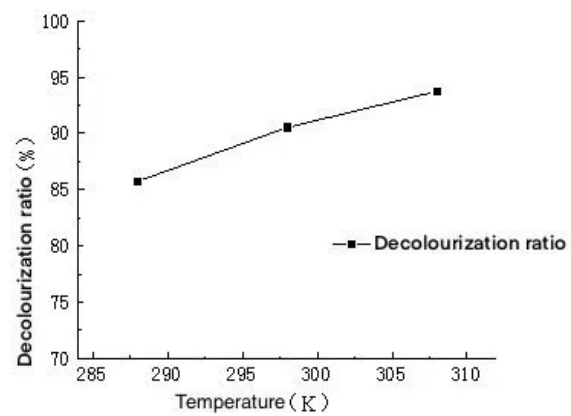

Fig6. Effect of temperature on decolorization rate of Methylene Blue adsorbed by Fe3O4@GO

It can be seen from the picture that the unit adsorption capacity of the composite material and the decolorization rate of the solution increase as the temperature increases. The reaction temperature increases from $15^{\circ} \mathrm{C}$ to $35^{\circ} \mathrm{C}$. The unit adsorption capacity of the composite material for methylene blue increases from $85.79 \mathrm{mg} / \mathrm{L}$ increased to $94.22 \mathrm{mg} / \mathrm{L}$, the decolorization rate increased from $86.67 \%$ to $94.00 \%$, The adsorption effect increases with the increase of temperature, compounding the objective law.However, considering that the method of increasing the temperature is rarely used in the actual industrial wastewater treatment to improve the reaction effect of the adsorption reaction, combined with the actual situation, the subsequent experiment should not increase the temperature in order to improve the adsorption effect, and continue to use $25^{\circ} \mathrm{C}$ as the reaction condition.

\subsection{The effect of adsorbent dosage on adsorption test}

The dosage of adsorbent is also an important factor affecting the adsorption test.In order to examine the effect of the adsorbent dosage on the adsorption test, the conditions that remain unchanged in this experiment are set as follows: $\mathrm{pH}=7.00$, methylene blue concentration $99.7 \mathrm{mg} / \mathrm{L}$, raw water chromaticity 1307.13 times, reaction temperature $15^{\circ} \mathrm{C}$, contact time $1440 \mathrm{~min}$.Add different amounts of $\mathrm{Fe}_{3} \mathrm{O}_{4} @ \mathrm{GO}$ adsorbent, measure the absorbance and chromaticity of water, and calculate the unit adsorption amount of adsorbate and methylene blue decolorization rate. The experimental results are shown in Figure 7 and Figure 8.

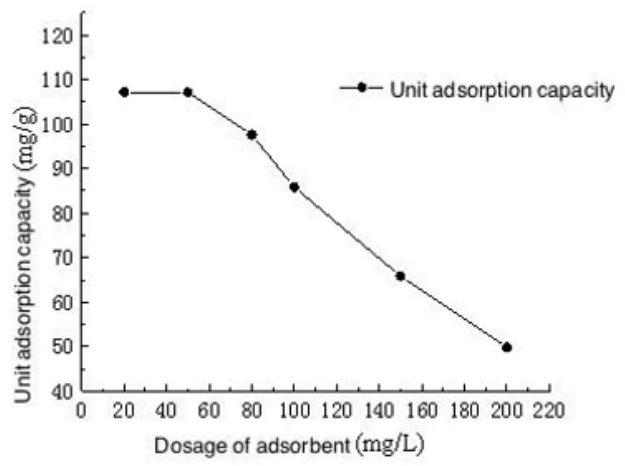

Fig7. Effect of dosage of sdsorben on Methylene Blue unit adsorption capacity of Fe3O4@GO

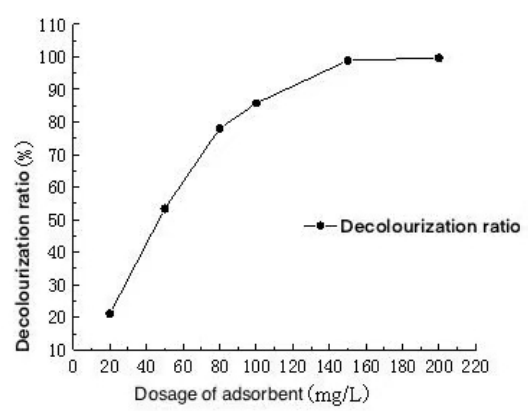

Fig8. Effect of dosage of sdsorben on decolorization rate of Methylene Blue adsorbed by Fe3O4@GO

From the picture, we can see that the decolorization rate gradually increases as the adsorbent dosage increases until it approaches $100 \%$, and as the adsorbent dosage increases, the adsorption capacity per unit mass of the composite material decreases. When the initial adsorbent dosage is $0.2 \mathrm{~g} / \mathrm{L}$ and $0.5 \mathrm{~g} / \mathrm{L}$, the unit adsorption capacity is $107.23 \mathrm{mg} / \mathrm{g}$ and $107.15 \mathrm{mg} / \mathrm{g}$, respectively, with little change.Therefore, we believe that when the adsorbent dosage is less than $0.5 \mathrm{~g} / \mathrm{L}$ in $100 \mathrm{mg} / \mathrm{L}$ methylene blue solution, the adsorption is close to saturation, and the saturated adsorption capacity is $107.23 \mathrm{mg} / \mathrm{L}$ 


\section{Conclusion}

1.The experimental analysis shows that when the $\mathrm{pH}$ value is different, the protons in the water and the charge valence state of the adsorbent surface may affect the adsorption effect, and the adsorption removal effect is more ideal in alkaline and neutral environments. And when the $\mathrm{pH}$ is between 7 and 8 , the adsorption effect is optimal, and the removal rate and the unit adsorption capacity are not changing significantly when the $\mathrm{pH}$ value continues to increase. Test control $\mathrm{pH}=7$ is the best.

2.The test analysis shows that as the contact time increases, the unit adsorption capacity and decolorization rate continue to increase, and the adsorption speed gradually slows down until the contact time reaches 1000 minutes and the adsorption is close to equilibrium.Continue to increase the contact time, the unit adsorption capacity and decolorization rate will continue to increase, but the increase is no longer obvious. For the convenience of control, it is best to control the reaction time to 1440 minutes.

3.The test analysis shows that as the reaction temperature increases, the unit adsorption capacity and the decolorization rate of the solution increase, but as the reaction temperature increases, the adsorption speed tends to slow down. In order to facilitate control, the reaction temperature is controlled to $25^{\circ} \mathrm{C}$ optimal.

4.The test analysis shows that with the continuous increase of the adsorbent dosage, the decolorization rate gradually increases with the increase in the adsorbent dosage until it approaches $100 \%$, but the adsorption capacity per unit mass of the composite material decreases accordingly. When the dosage is $0.5 \mathrm{~g} / \mathrm{L}$, the unit adsorption capacity of methylene blue by the adsorbent is the maximum

5. When the pH is 7 8, the $\mathrm{Fe}_{3} \mathrm{O}_{4} @ \mathrm{GO}$ composite material has the best adsorption effect on methylene blue, and whether the $\mathrm{pH}$ increases or decreases, the adsorption effect will be affected; With the increase of the contact time, the amount of adsorption continues to increase, and the increase gradually slows down from the very fast at the beginning, until the adsorption is close to equilibrium at about $1000 \mathrm{~min}$;Adsorption is an endothermic reaction. As the temperature increases, the amount of adsorption increases, but the temperature has little effect on the adsorption reaction. It is not recommended to increase the temperature in order to improve the adsorption effect in actual projects; The concentration of raw water adsorbent and the dosage of adsorbent are a pair of dynamic influencing factors, Ionic strength in water has a low impact on the adsorption test.Three sets of parallel adsorption experiments were carried out under optimized conditions. In the three sets of experiments, the maximum unit adsorption capacity of the composite material for methylene blue was $107.68 \mathrm{mg} / \mathrm{g}$, and the adsorption was stable, indicating that the self-made composite material had a better adsorption effect on methylene blue and was used as a dye adsorbent.There is further research value.

\section{Acknowledgments}

This article is one of the phased results of the National Social Science Fund's general project "China National Critical Project for Science and Technology on Water Pollution Prevention and Control" (2018ZX07601001), and thank you for the help of teachers and students on the paper.

\section{References}

1. Liu Xiaping, Wang Huicai,Sun Qiang, Yang Jiwu et al.Research progress of graphene, 3D graphene and their composite materials [J]. Chemical progress. 37(1):168-174,(2018).

2. Zhu Hongwen, Duan Zhengkang, Zhang Lei. Research progress on the preparation and structure of graphene oxide $[\mathrm{J}]$. Materials Science and Technology, 25(6):82-88,(2017).

3. Zhang Qian,Tang Libin,Li Rujie Progress in preparation, reduction and application of graphene oxide[J]. Journal of Infrared and Millimeter Waves, 38(1):79-90,(2019).

4. Zhou Li, Deng Huiping, Wan Junli, Wan Junli et al.Preparation of graphene-based iron oxide magnetic material and its adsorption performance in water treatment[J]. Chemical progress , 25(1):144155,(2013).

5. Zhang D, Ma Y, Feng H , et al. Removal of Methylene Blue from aqueous solution by a carbonmicrosilica composite adsorbent[J]. Korean Journal of Chemical Engineering, , 29(6):775-780(2012). 